Gut, 1989, 30, 880-881

Case report

\title{
Dukes A carcinoma after colonic interposition for oesophageal stricture
}

\author{
A D HOUGHTON, M JOURDAN, AND I MCCOLL \\ From the Department of Surgery, Guy's Hospital, London
}

SUMmary The management of caustic and peptic oesophageal strictures refractory to medical treatment and repeated dilatations continues to be a challenge. Colonic interposition with subtotal oesophagectomy is felt by many surgeons to be the best treatment. ${ }^{2}$ Complications in the short and long term are, however, frequent. ${ }^{3}$ We report a case of a colonic carcinoma originating in a colonic interposition and growing up into the oesophageal remnant.

Case report

A 64 year old man who 20 years previously had undergone interposition of the right colon between the upper oesophagus and stomach for benign oesophageal stricture presented with a three month history of progressive dysphagia with weight loss.

Barium swallow revealed a polypoid oesophageal growth which on computed tomography scanning was limited to the oesophagus with no evidence of pulmonary or liver metastases. Endoscopic biopsy showed adenocarcinoma. The tumour, colonic interposition, and remnant intrathoracic oesophagus were resected in continuity and gastric interposition carried out using the Ivor Lewis technique. After a normal gastrograffin swallow at six days the patient was discharged at 10 days eating normally. Histology showed a Dukes A carcinoma arising in a colonic villous adenoma. Subsequent colonoscopy was normal.

Address for correspondence: Mr A D Houghton. FRCS. Guy's Hospital, St Thomas St, London SEl GRT.

Accepted for publication 28 Octoher 1988.
Discussion

Colonic interposition for benign oesophageal strictures carries a perioperative mortality of $5-8 \%^{1-3}$ and a high morbidity. Gangrene of the interposed colon occurs in up to $9 \%$ of cases and is the result of venous infarction. ${ }^{2}$ Leakage of the oesophagocolic anastomosis may also occur, ${ }^{23}$ although this may be less common than with oesophagogastric anastomoses. ' Other complications include stricture of the graft and 'the redundant graft'. This redundant graft described initially by Belsey ${ }^{4}$ and not improving with time consists of dilatation of the graft with resulting food and fluid retention. Other infrequent late complications include ulceration and colitis in the colonic segment ${ }^{3}$ and one report of a perforated colonic ulcer $4 \mathrm{~cm}$ proximal to the stomach.

Colonic carcinoma has been reported once previously, and this also appears to have been malignant change in a villous adenoma. ${ }^{5}$ This finding and our case emphasises the importance of considering the possibility of colonic malignancy in a dysphagic patient after interposition of the colon for either a benign or malignant oesophageal stricture. It is particularly relevant where colonic interposition has been done for benign disease when the subject may 
be young and life expectancy long. The colonic malignancy in this case will carry a very much better prognosis than a primary oesophageal carcinoma. A history of colonic polyps, colitis, and a positive family history of colonic carcinoma would be expected to make malignant change in the colon interposition more likely.

We are grateful to Mr B Hartley, Consultant Histopathologist, Guy's Hospital for his help with this case.

\section{References}

I Keenan J, Hamilton J, Gibbons J, Stevenson H. Surgery for benign oesophageal stricture. J Thorac Cardiovasc Surg 1984; 88: 182-8.

2 Skinner D. Esophageal reconstruction. Am J Surg 1980; 139: 810-4.

3 Mullen D, Postlethwaite M, Dillon M. Complications of substernal colon interposition. Am Surg 1970; 36: 80-4.

4 Belsey R. Reconstruction of the oesophagus with left colon. J Thorac Cardiovasc Surg 1965; 49: 33.

5 Goldsmith H, Beattie Jr. Malignant villous tumour in a colon bypass. Ann Surg 1968; 167: 98. 